mgr inz. Tomasz Gazdulski

Instytut Pojazdów Szynowych ,TABOR”

dr inz. Bartosz Czechyra

Politechnika Poznańska

\title{
Badania klimatu akustycznego pojazdu szynowo-drogowego w warunkach normalnej eksploatacji
}

\begin{abstract}
Pojazdy szynowo-drogowe sq klasq obiektów technicznych, które coraz częściej występuja w parku maszynowym operatorów tramwajowych i kolejowych. Sq to zazwyczaj pojazdy specjalnie przystosowane do prac ratowniczych oraz obstugowych dużej infrastruktury. Zadaniem prezentowanego pojazdu jest ułatwienie utrzymania $w$ czystości torowisk i przystanków tramwajowych. Niezależnie od typu pojazdu oraz jego cech funkcjonalnych musi on spetniać wszystkie wymagania ochrony kierowcy $w$ zakresie narażenia na drgania $i$ hatas na stanowisku pracy.

Artykut dotyczy problemu pomiaru hałasu wystepujacego podczas eksploatacji pojazdu szynowo-drogowego. Wartykule omówione zostaty badania terenowe przeprowadzone na pojeździe szynowo-dorgowym IVECO-eurocargo TC-2 przeznaczonego do oczyszczania torów tramwajowych. Zaprezentowany zostat badany obiekt oraz metodyka badań stworzona dla tego obiektu. Przedstawiono, także wyniki badań terenowych, które byty prowadzone $w$ aspekcie oddzialywania hatasu, wystepujacego wewnatrz pojazdu podczas jazdy oraz postoju na organizm człowieka.
\end{abstract}

\section{Wprowadzenie}

Hałas generowany przez pojazdy drogowe oraz szynowe jest zjawiskiem niepożąalanym. W skrajnych przypadkach może być uciążliwym elementem naszego otoczenia a nawet szkodliwym w codziennym życiu człowieka. Wynikiem zrozumienia negatywnego wpływu hałasu na organizm człowieka 
jest otwarta i ożywiona dyskusja prowadzona przez różne środowiska (w tym naukowe) oraz wszczęty proces legislacyjny na poziomie Unii Europejskiej.

Zjawiskowe pole wibroakustyczne generowane $\mathrm{w}$ wyniku eksploatacji pojazdów drogowych i szynowych ma wpływ na zakłócenia aktywności człowieka - zarówno pasażerów jak i operatorów pojazdów (kierowcy, maszynisty czy motorniczego). Powszechnie wiadomo, że moga powodować odczucie dyskomfortu, przemęczenia, wpływają niekorzystnie na narząd słuchu, układ nerwowy oraz krążenia. Nadmierna ekspozycja człowieka na hałas o wysokim poziomie jest przyczyną zaburzeń poczucia bezpieczeństwa i niezależności, zakłóca porozumiewanie się oraz orientację w środowisku pracy i codziennego życia. W konsekwencji długotrwałego oddziaływania hałasu może dojść do wystapienia określonych jednostek chorobowych, a w skrajnych przypadkach nawet do śmierci.

Pojazdy szynowo-drogowe są środkami transportu o coraz szerszym zastosowaniu. Wynika to $\mathrm{z}$ wielu zalet jakie posiadają, a należą do nich niewątpliwie [3]:

- niski koszt budowy w porównaniu z typowymi pojazdami szynowymi,

- niskie koszty eksploatacji, obsługi i napraw związane przede wszystkim z małym zużyciem oleju napędowego i środków smarnych,

- duża dyspozycja i pełne wykorzystanie w pracach na torze i drodze,

- możliwość postoju w typowym dla pojazdów drogowych garażu lub pod wiata,

- możliwość dojazdu do miejsc pracy na torze, drogami kołowymi,

- wysoka niezawodność i bezpieczeństwo w pracach na torze i drodze.

To powoduje, iż pojazdy szynowo-drogowe z powodzeniem zastępują małe lokomotywy manewrowe na bocznicach kolejowych, w zakładach przemysłowych oraz kopalniach. Jednakże mimo wielu zalet istnieją pewne zagrożenia wynikające ze sposobu tworzenia tego typu pojazdów tj. przekonstruowania standardowych pojazdów drogowych. Do tych zagrożeń można zaliczyć możliwość pojawienia się lokalnych rezonansów konstrukcji, które mogą przełożyć się na wysoki poziom hałasu na stanowisku operatora. Dodatkowo sytuację utrudnia brak jednoznacznych przepisów i dokumentów regulujących pomiar hałasu w pojazdach specjalnych, do których niewątpliwie należą pojazdy szynowo-drogowe.

Celem artykułu jest przedstawienie metodyki pomiarowej oraz wyników przeprowadzonych badań terenowych pomiaru hałasu oddziałującego na operatora w kabinie pojazdu szynowo-drogowego. Pomiarami objęto pojazd szynowo-drogowy służący do oczyszczania infrastruktury tramwajowej w Poznań.

\section{Obiekt badań}

Obiektem badań był specjalistyczny pojazd szynowo-drogowy IVECO EUROCAGO typu TC-2, którego dokumentacja konstrukcyjna i prototyp opracowane zostały w Instytucie Pojazdów Szynowych „TABOR” w Poznaniu. Konstrukcja pojazdu opierała się na seryjnym podwoziu IVECO EUROCARGO Model 140E18W o wzmocnionej konstrukcji. Poprzez dodatkowe wyposażenie pojazdu w szynowy układ jezdny pojazd przystosowany został do poruszania się zarówno po drogach jak i po torach tramwajowych. Widok pojazdu drogowo-szynowego gotowego do pracy przedstawiono na rysunku 1 .

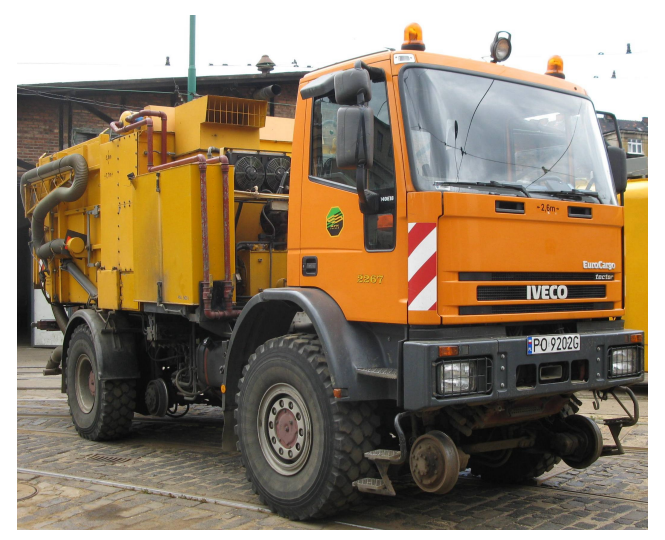

Rys. 1. Pojazd szynowo-drogowy do oczyszczania infrastruktury tramwajowej

Omawiany pojazd został opracowany z myślą o wykonywaniu podstawowych prac związanych $\mathrm{z}$ oczyszczaniem torowiska (w tym rozjazdów i krzyżownic) oraz jego najbliższego otoczenia. Jednocześnie zostały zaimplementowane dodatkowe funkcjonalności odróżniające ten pojazd od innych dostępnych na rynku [4]. Pojazd umożliwia oczyszczanie $\mathrm{z}$ różnego rodzaju zanieczyszczeń stałych torowisk tramwajowych wydzielonych i wspólnych $z$ jezdnia, międzytorza torowiska wydzielonego oraz powierzchni przystanków tramwajowych.

Widok na sposób prowadzenia prac utrzymania infrastruktury przedstawiono na rysunku 2 .

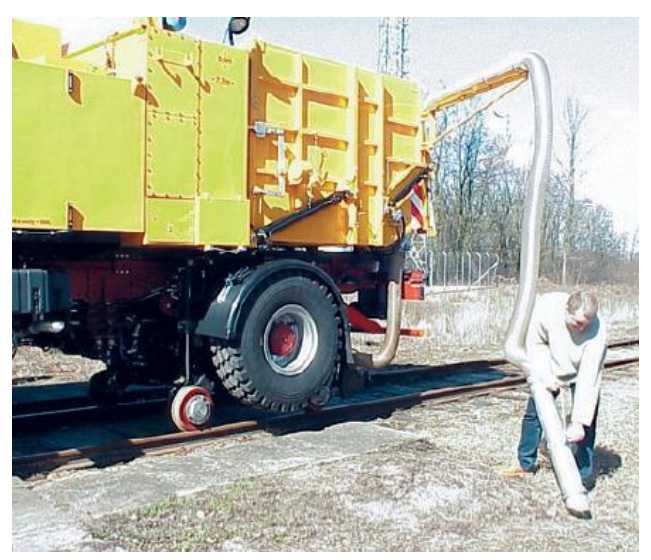

Rys. 2. Wykorzystanie ssawy ręcznej do oczyszczania powierzchni przystanku [2] 
Znaczą zaletą pojazdu jest możliwość automatycznego oczyszczania rowków szyn tramwajowych z piasku, kamieni oraz innych elementów drewnianych, metalowych itp. Znacząco wpływając na bezpośrednie podwyższenie bezpieczeństwa jazdy tramwaju w torze. Widok na układ oczyszczania rowków szyn tramwajowych zamieszczono na rysunku 3.

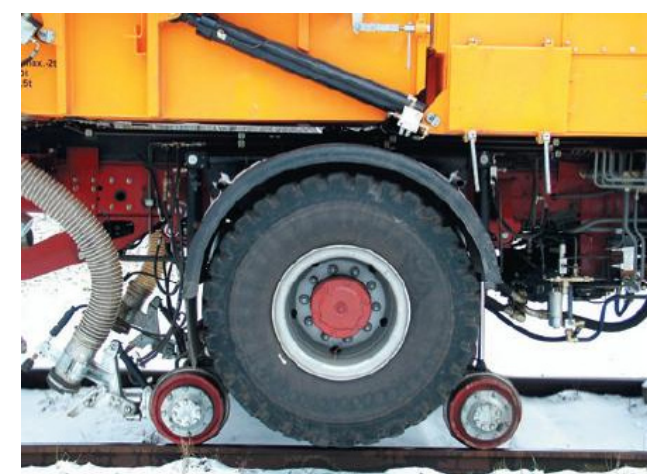

Rys. 3. Widok na skrobak i ssawę do oczyszczania rowków szyn [2]

Tak zaprojektowany pojazd został wprowadzony do eksploatacji w Miejskim Przedsiębiorstwie Komunikacji w Poznaniu.

\section{Metodyka badań \\ 3.1. Miejsce pomiarów}

Ze względu na brak szczegółowych przepisów precyzujących pomiary w pojeździe drogowoszynowym w badaniach wykorzystano normy dotyczące pomiaru hałasu na stanowisku operatora pojazdu kołowego w reprezentacyjnych warunkach eksploatacyjnych.

Ze względu na chęć minimalizowani wpływu postronnych pojazdów oraz innych źródeł dźwięku na wyniki prowadzonych badań pomiary wykonano nocą z 22.06.2010 na 23.06.2010 pomiędzy godziną $23^{40}$ a $2^{50}$. Pomiarów dokonano $\mathrm{w}$ ruchu podczas jazdy pojazdu po drodze kołowej (na odcinkach ulic: Hetmańska, Żegrze i po torach tramwajowych (na odcinkach ulic: Zwierzyniecka, Józefa Kraszewskiego, Jana Henryka Dąbrowskiego i Franklina Roosvelta. Obie lokalizacje przedstawiono odpowiednio na rysunkach 4 i 5.

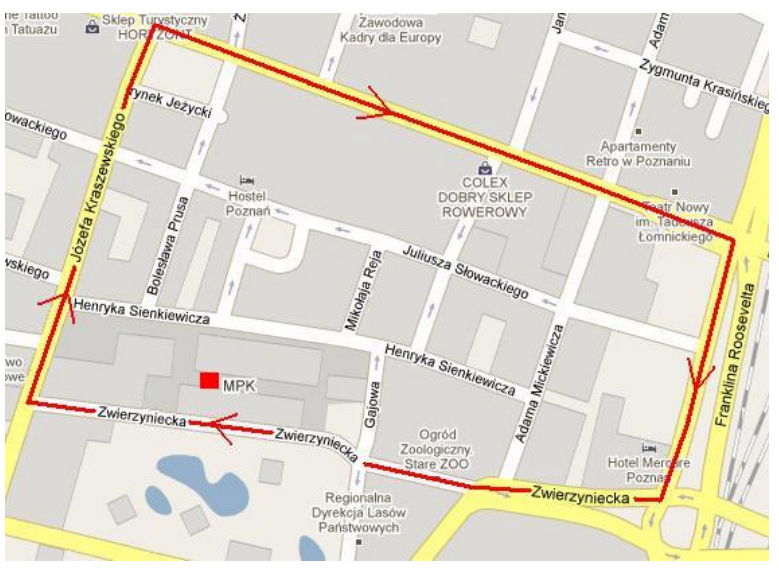

Rys. 5. Trasa przejazdu po torach oraz miejsce wykonywania pomiary na postoju [1]

Natomiast badanie na postoju wykonano na terenie zajezdni tramwajowej przy ulicy Gajowej (oznaczone kwadratem na rysunku 5).

\subsection{Aparatura pomiarowa i punkty pomiarowe}

Punkt pomiaru hałasu w pojeździe podczas jazdy i postoju został dobrany zgodnie z wymaganiami norm PN-ISO 9612 [7], PN-92 K-11000 [5] i PN-S-04052 [10] przyjmując rodzaj samochodu $\mathrm{z}$ jednym rzędem siedzeń. Mikrofon umieszczono na wysokości 700 $\mathrm{mm}$ nad powierzchnią siedzenia przy uchu operatora w odległości co najmniej $200 \mathrm{~mm}$ (punkt 4.1 normy PN-N-01307 [9]) do środka pojazdu. Na rysunku 6 przedstawiono lokalizację punktu pomiarowego.
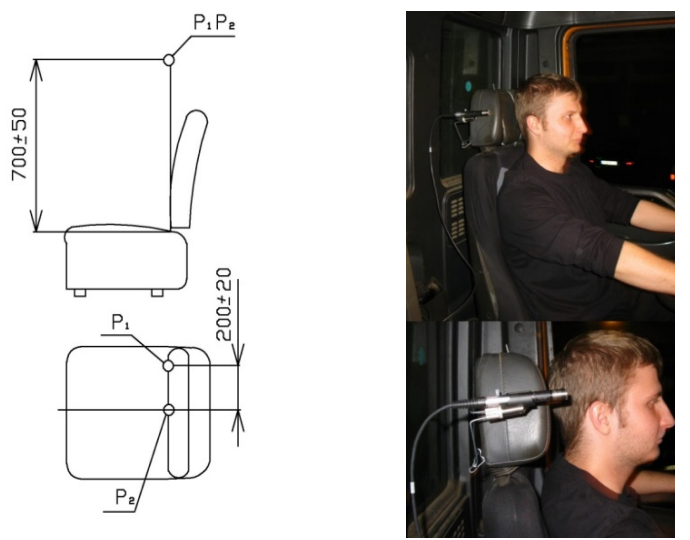

Rys. 6. Umieszczenie mikrofonu wg normy i w pojeździe [10]

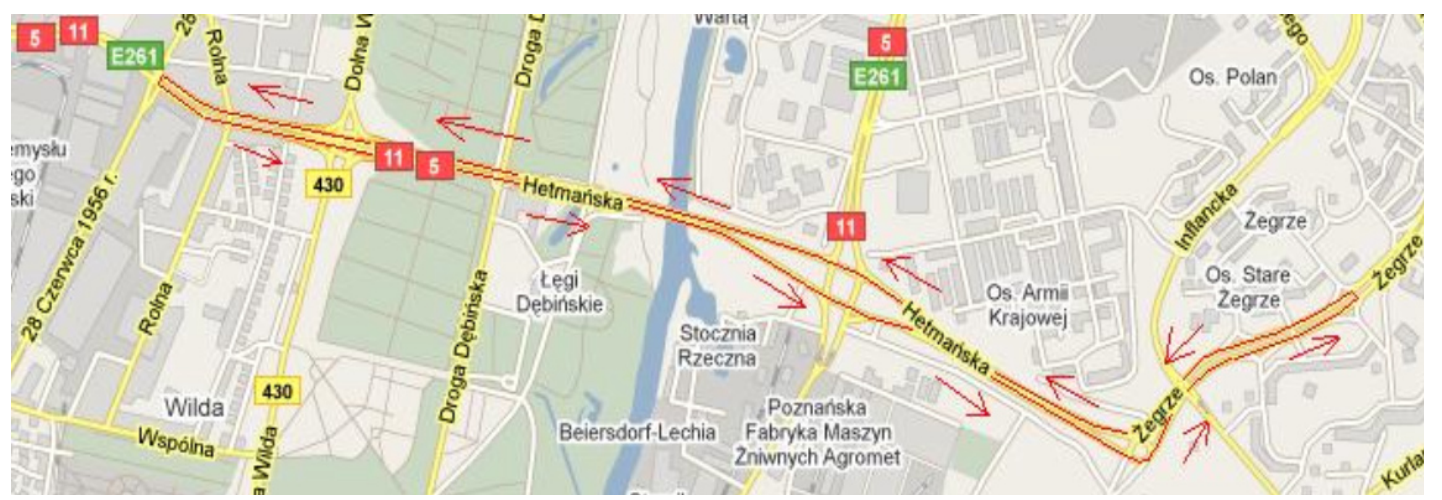

Rys. 4. Trasa przejazdu na kołach gumowych [1] 
Wszystkie pomiary hałasu zostały wykonane całkującym miernikiem hałasu typu 2250 firmy Brüel\&Kjaer. szczegółowy opis urządzenia pomiarowego na stronie producenta [12].

\subsection{Procedura pomiarowa}

Badania hałasu dokonano poprzez pomiar równoważnego poziomu dźwięku Li w punkcie pomiarowym przedstawionym powyżej.

Pomiaru równoważnego poziomu dźwięku na postoju dokonano przy pracującym silniku spalinowym z obrotami $700 \mathrm{~min}^{-1}$ oraz przy pracującym silniku na 4 biegu z obrotami $1700 \mathrm{~min}^{-1}$ i włączonym wentylatorze. Łącznie dokonano czterech pomiarów, z których każdy trwał $180 \mathrm{~s}$.

Natomiast pomiary równoważnego poziomu dźwięku podczas ruchu pojazdu wykonano oddzielnie na drodze kołowej i torze. Badania na drodze kołowej zostały wykonane przy stałej prędkości v $=50$ $\mathrm{km} / \mathrm{h}$. Dokonano dwóch pomiarów, z których każdy trwał $240 \mathrm{~s}$.

Badania na torze zostały wykonane przy dwóch stałych prędkościach: roboczej po torze prostym $\mathrm{v}=0,8 \mathrm{~km} / \mathrm{h}$ i dojazdowej po torze prostym $\mathrm{v}=7,8$ $\mathrm{km} / \mathrm{h}$. Dla każdej prędkości dokonano dwóch pomiarów, z których dla prędkości $\mathrm{v}=0,8 \mathrm{~km} / \mathrm{h}$ trwał $480 \mathrm{~s}$, natomiast dla prędkości $v=7,8 \mathrm{~km} / \mathrm{h}$ trwał $300 \mathrm{~s}$.

$\mathrm{Na}$ podstawie zmierzonych wartości równoważnego poziomu dźwięku Li dla każdej czynności to jest postoju, jazdy po drodze kołowej $\mathrm{z}$ prędkością $\mathrm{v}=50 \mathrm{~km} / \mathrm{h}$ i torze $\mathrm{z}$ prędkościami $\mathrm{v}=0,8 \mathrm{~km} / \mathrm{h}$ i v $=7,8$ $\mathrm{km} / \mathrm{h}$ zostały wyznaczone: średnia wartość równoważnego poziomu dźwięku $\mathrm{L}_{\text {Aeq }}$ zgodnie $\mathrm{z}$ zależnością wskazaną w normie PN-N-01306 [8]:

$$
L_{\text {Aeq }}=10 \log \left[\frac{1}{n} \sum_{i=1}^{n} 10^{0,1 \cdot L_{i}}\right]
$$

gdzie:

n- liczba pomiarów

$\mathrm{L}_{\mathrm{i}}$ - zmierzony równoważny poziom dźwięku $\mathrm{w}$ $[\mathrm{dB}]$ oraz poziom ekspozycji na hałas odniesiony do 8-godzinnego dnia pracy $\mathrm{L}_{\mathrm{EX}, 8 \mathrm{~h}}$ zgodnie $\mathrm{z}$ zależnością wskazaną $\mathrm{w}$ normie PN-ISO 1999:2000 [6]:

$$
L_{E X, 8 h}=L_{A e q}+10 \lg \left(T_{e} / T_{0}\right)
$$

gdzie:

- $\mathrm{L}_{\text {Aeq }}-$ wartość równoważnego poziomu dźwięku

$-\mathrm{T}_{\mathrm{e}}-$ efektywny czas dnia pracy

- $\mathrm{T}_{0}$ - czas odniesienia $(=8 \mathrm{~h})$.

Wyniki porównano $\mathrm{z}$ wartościami (tabela 1) zawartymi w Rozporządzeniu Ministra Gospodarki i Pracy z dnia 5 sierpnia 2005 r. [11] oraz normach PN-90/S-04052 [10] i PN 92/K11000 [5]

\begin{tabular}{|c|l|}
\hline Dokument & \multicolumn{1}{|c|}{ Wartość } \\
\hline $\begin{array}{c}\text { Rozporządzenie } \\
\text { Ministra Go- } \\
\text { spodarki i } \\
\text { Pracy z dnia 5 } \\
\text { sierpnia 2005 r. }\end{array}$ & $\begin{array}{l}\text { Poziom ekspozycji na hałas odniesiony do 8- } \\
\text { godzinnego dobowego wymiaru czasu pracy } \\
\text { lub poziom ekspozycji na hałas odniesiony } \\
\text { do tygodnia pracy - wartość progu działania } \\
\text { wynosi 80 dB }\end{array}$ \\
\hline PN-90/S- & $\begin{array}{l}\text { Dopuszczalny poziom hałasu dla samocho- } \\
\text { dów ciężarowych - 80 dB }\end{array}$ \\
\hline PN & $\begin{array}{l}\text { Dopuszczalny poziom hałasu na stanowisku } \\
\text { maszynisty i pomocnika maszynisty pojazdu } \\
\text { trakcyjnego - 78 dB }\end{array}$ \\
\hline
\end{tabular}

\section{Wyniki badań}

Pomiary hałasu wewnattrz pojazdu szynowodrogowego przeprowadzono podczas postoju oraz podczas jazdy po drodze kołowej i szynowej z różnymi prędkościami. Odpowiednio na rysunkach 7, $8 \mathrm{i}$ 9 przedstawiono zestawienie wartości równoważnych poziomów dźwięku $\mathrm{L}_{\text {Aeq }}$ wewnątrz pojazdu $\mathrm{z}$ wartością dopuszczalną zawartą w normie PN-92/K-11000 [5], zestawienie wartości równoważnych poziomów dźwięku $\mathrm{L}_{\text {Aeq }}$ wewnątrz pojazdu $z$ wartością dopuszczalną zawartą w normie PN-90/S-04052 [10] oraz zestawienie wartości poziomów dziennych ekspozycji na hałas $\mathrm{L}_{\mathrm{EX}, 8 \mathrm{z}} \mathrm{z}$ wartością dopuszczalną zawartą w Rozporządzeniu Ministra Gospodarki i Pracy z dnia 5 sierpnia 2005 r. [11].

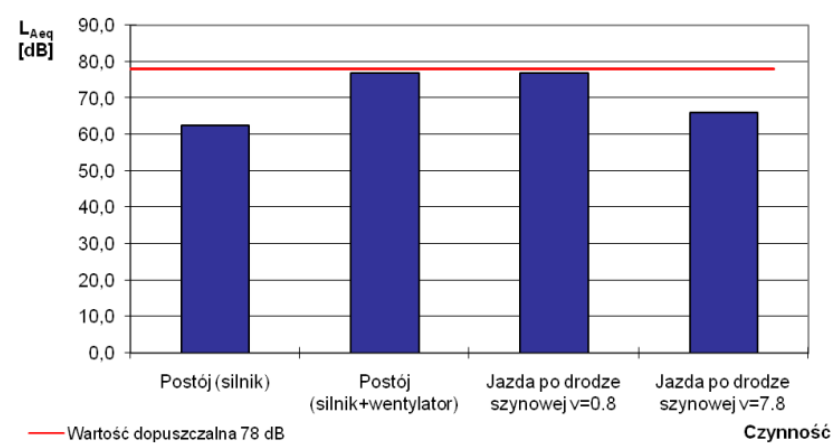

Rys. 7. Zestawienie wartości równoważnych poziomów dźwięku $\mathrm{L}_{\text {Aeq }}$ wewnątrz pojazdu $\mathrm{z}$ wartością dopuszczalną

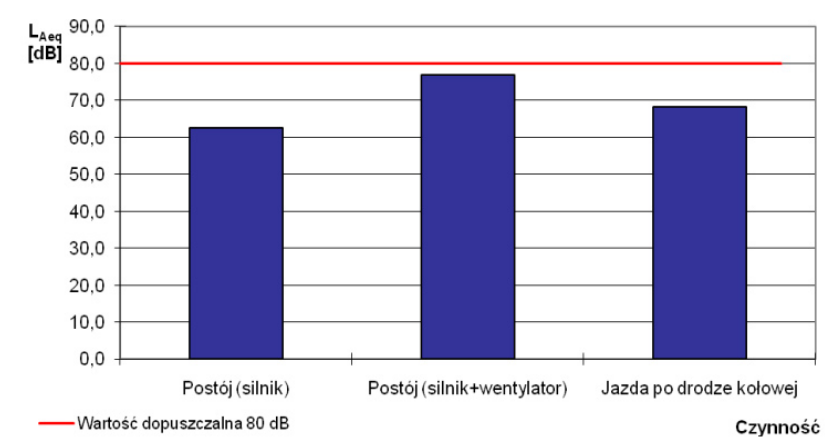

Rys. 8. Zestawienie wartości równoważnych poziomów dźwięku

$\mathrm{L}_{\text {Aeq }}$ wewnątrz pojazdu $\mathrm{z}$ wartością dopuszczalną zawartą $\mathrm{w}$ normie PN-90/S-04052 


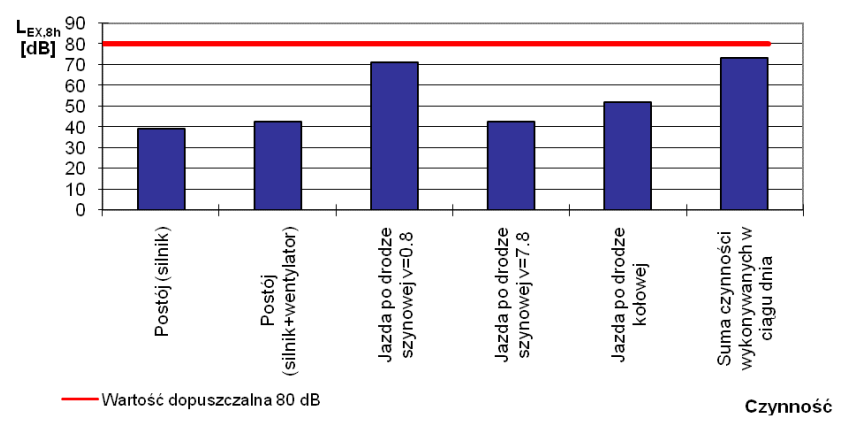

Rys. 9. Zestawienie wartości poziomów dziennych ekspozycji na hałas $\mathrm{L}_{\mathrm{EX}, 8 \mathrm{~h}} \mathrm{Z}$ wartością dopuszczalną zawartą w Rozporządzeniu Ministra Gospodarki i Pracy z dnia 5 sierpnia 2005 r.

Przeprowadzone pomiary wykazały, że pojazd nie przekracza dopuszczalnych wartości zawartych w obowiązujących przepisach. Jednakże podczas postoju z silnikiem pracującym na biegu jałowym oraz wentylatorem a także w czasie jazdy po drodze szynowej z prędkością $0,8 \mathrm{~km} / \mathrm{h}$ wartości równoważnego poziomu dźwięku zbliżają się do wartości dopuszczalnej (rys.6).

Wartości poziomów dziennych ekspozycji na hałas $\mathrm{L}_{\mathrm{EX}, \text {,sh }}$ (rys. 9) nie przekraczają wartości dopuszczalnej zawartej w Rozporządzeniu Gospodarki i Pracy z dnia 5 sierpnia 2005 r. Na tej podstawie można stwierdzić, że badany pojazd drogowoszynowy nie stanowi zagrożenia dla operatora $\mathrm{w}$ zakresie negatywnego oddziaływania hałasu na stanowisku pracy.

\section{Podsumowanie}

W artykule przedstawiono kompleksową metodykę badań hałasu w pojeździe szynowo-drogowym oraz zaprezentowano wyniki badań.

$\mathrm{Na}$ podstawie przeprowadzonych pomiarów sformułowano następujące wnioski:

- stworzona metodyka, przeprowadzone badania oraz analiza zarejestrowanych sygnałów pozwoliła przeprowadzić ocenę pojazdu szynowodrogowego zgodnie $\mathrm{z}$ obowiązującymi przepisami,

- nie zaobserwowano przekroczenia dopuszczalnych wartości równoważnego poziomu ciśnienia akustycznego,

- nie zaobserwowano przekroczenia wartości dopuszczalnych poziomów dziennych ekspozycji na hałas,
- największe wartości równoważnego poziomu ciśnienia akustycznego wahały się w granicach $77 \mathrm{~dB}$ podczas postoju pojazdu $\mathrm{z}$ włączonym silnikiem i wentylatorem oraz podczas jazdy po drodze szynowej $\mathrm{z}$ prędkością $0,8 \mathrm{~km} / \mathrm{h}$. Powodem tego jest praca wentylatora umieszczonego tuż za kabiną operatora.

\section{Literatura}

[1] http://maps.google.pl/, (lipiec 2010 r.).

[2] Medwid M.: Hybrydowe pojazdy kolejowo-drogowe zaprojektowane $i$ wytwarzane wPolsce. Technika Transportu Szynowego. 2005, nr 7-8.

[3] Medwid M., Marciniak Z.: Pojazdy szynowo-drogowe. Poznań 1999.

[4] Medwid M., Przepióra K.: Pojazd szynowo-drogowy do oczyszczania infrastruktury tramwajowej. Pojazdy Szynowe 2003, $n r 4$.

[5] Norma PN-92/K-11000 Tabor kolejowy. Hałas. Ogólne wymagania i badania. Wytyczne do wykonywania pomiarów na stanowisku pracy.

[6] Norma PN-ISO 1999:2000 Akustyka. Wyznaczanie ekspozycji zawodowej na halas iszacowanie uszkodzenia stuchu wywotanego hałasem.

[7] Norma PN-ISO 9612:2004 Akustyka. Wytyczne do pomiarów i oceny ekspozycji na hałas w środowisku pracy.

[8] Norma PN-N-01306:1981 Halas. Metody pomiaru. Wymagania ogólne.

[9] Norma PN-N-01307:1994 Hatas. Dopuszczalne wartości parametrów hatasu w środowisku pracy. Wymagania dotyczace wykonywania pomiarów.

[10]Norma PN-S-04052:1990 Samochody. Dopuszczalny poziom hatasu wewnatrz pojazdu. Wymagania i badania.

[11] Rozporzadzenie Ministra Gospodarki i Pracy z dnia 5 sierpnia 2005 r. w sprawie bezpieczeństwa i higieny pracy przy pracach zwiazanych z narażeniem na hatas lub drgania mechaniczne. Dz. U. nr 157, poz. 318.

[12] www.bksv.com 